\title{
OUTLINE OF SEISMIC RETROFITTING OF RAILWAY RC STRUCTURES
}

\author{
Tadayoshi ISHIBASHI $^{1}$ and Takeshi TSUYOSHI ${ }^{2}$ \\ ${ }^{1}$ Manager, Structural Engineering Center, Construction Dept., JR East, \\ Tokyo, Japan, ishibashi@jreast.co.jp \\ ${ }^{2}$ Chief Engineer, Structural Engineering Center, Construction Dept., \\ Tokyo, Japan, tsuyoshi@jreast.co.jp
}

\begin{abstract}
Seismic retrofitting of RC columns and piers of railway structures has been carried out since the Hyogo-Ken Nanbu Earthquake in 1995. This paper first describes a seismic retrofitting design flow of existing RC columns and piers of railway structures and secondly introduces representative seismic retrofitting methods.
\end{abstract}

Key Words: seismic retrofitting design, seismic retrofitting methods, RC structures, railway structures

\section{INTRODUCTION}

By the Hyogo-Ken Nanbu earthquake on 17 January 1995, railway structures on the Sanyo Shinkansen Line and the Tokaido conventional Line were severely damaged. These are mainly collapses of RC rigid frame structures by shear failures of columns (Photo 1). In considerations of these damages of railway structures, the authorities at Ministry of Transportation issued a notification on seismic retrofitting to railway companies. Following the recommendations of this notification, the columns of RC rigid-frame structures having shear capacity smaller than the shear at flexural capacity

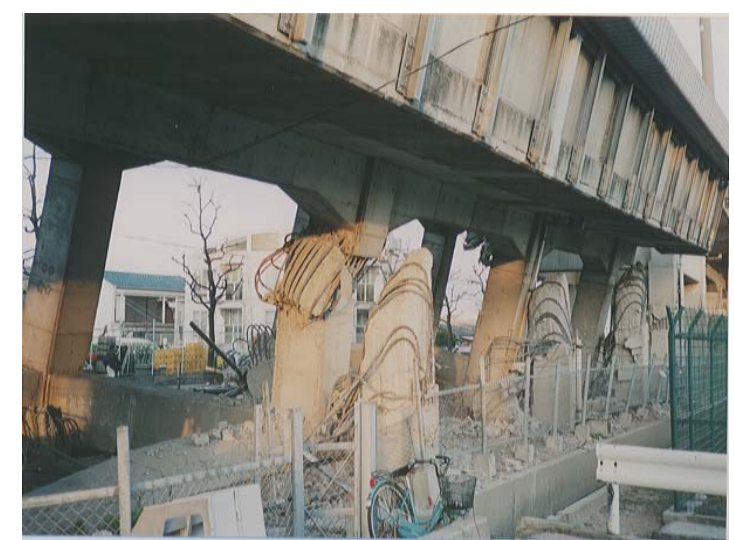

Photo 1 Damage of RC rigid frame structure 
were subject to seismic retrofitting. But, now, necessary seismic retrofitting works are not finished completely. And, by the Sanriku-Minami earthquake on 26 May 2003, droppings of cover concrete of RC columns of rigid frame structures were occurred on the Tohoku Shinkansen Line. Then, systematic and speedy completion of seismic retrofitting works of existing RC columns and piers is strongly expected.

On the other hand, the steel jacket method is mainly used to seismic retrofitting works of RC columns. However, spaces under railway viaducts are often used for stores and offices, especially in urban areas. Therefore, development of new seismic retrofitting methods applicable to these areas is one of the important issues for the improvement of railway lines' seismic safety.

This paper first describes a general seismic retrofitting design flow of existing RC columns of railway structures and secondly introduces of representative seismic retrofitting methods in East Japan Railway Company.

\section{GENERAL SEISMIC RETROFITTING DESIGN FLOW}

For seismic retrofitting of railway RC structures like rigid frame structures and piers, shear retrofitting and ductility retrofitting of columns and piers are the main focus. Fig.1 shows the seismic retrofitting design procedure. This seismic retrofitting design is carried out in order that structures are not collapsed by Level 2 earthquake which isvery large earthquake with rare possibility of occurrence in the design period.

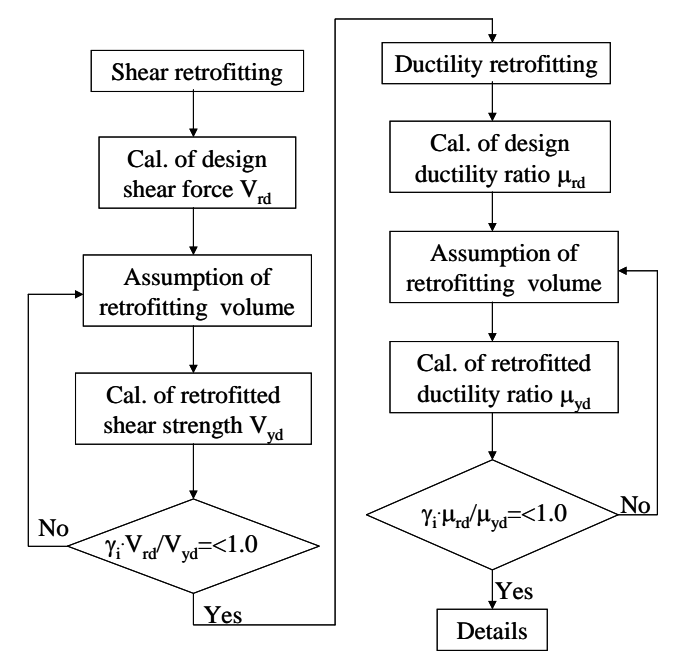

Fig.1 Seismic retrofitting design flow

\section{REPREZENTATIVE SEISMIC RETROFITTING METHODS}

\section{Reinforced concrete jacket method}

\section{Outline of reinforced concrete jacket method}

The reinforced concrete jacket method is used mainly at underground parts of columns. Fig.2 shows outline of this method. Photo 2 shows arrangements of retrofitting reinforcements in order to improve shear and ductility capacities of a column.

\section{Evaluation of flexural and shear capacity}

Flexural capacity is calculated by the same way of general RC columns. Shear capacity $V_{y d}$ is also 


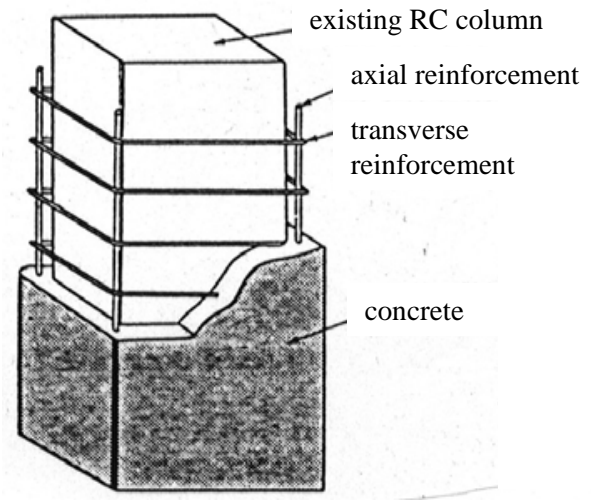

Fig.2 Outline of RC jacket method

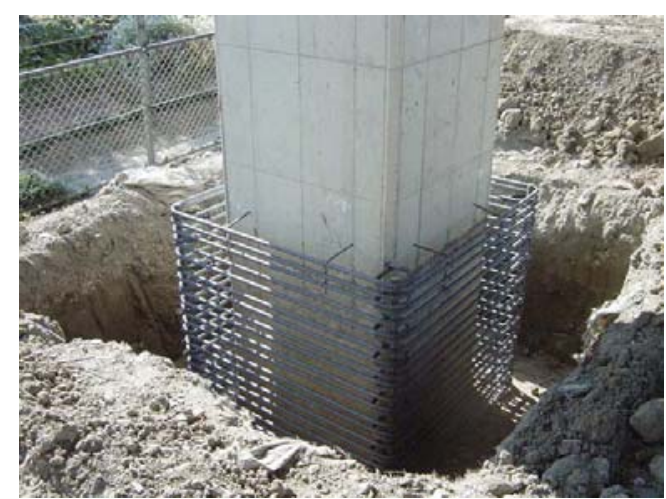

Photo 2 Arrangements of retrofitting reinforcements

calculated by the same of general RC columns and that is assumed as the sum of $\mathrm{V}_{\mathrm{c}}$ : shear strength held by concrete and $\mathrm{V}_{\mathrm{s}}$ : shear strength held by transverse reinforcements. The value of $\mathrm{V}_{\mathrm{c}}(\mathrm{N})$ : strength without shear reinforcements is estimated by the Eq.(1).

$$
\mathrm{V}_{\mathrm{c}}=\beta_{\mathrm{d}} \cdot \beta_{\mathrm{p}} \cdot \beta_{\mathrm{n}} \cdot \mathrm{f}_{\mathrm{vcd}} \cdot \mathrm{b}_{\mathrm{w}} \cdot \mathrm{d} / \gamma_{\mathrm{b}}
$$

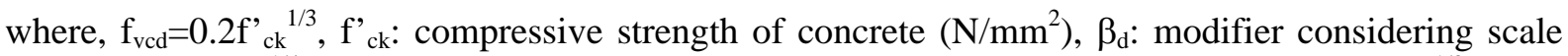
effect $=(1000 / \mathrm{d})^{1 / 4}=<1.5, \beta_{\mathrm{p}}$ : modifier considering amount of axial reinforcement $=\left(100 \mathrm{p}_{\mathrm{c}}\right)^{1 / 3}=<1.5$, $\beta_{\mathrm{n}}$ : modifier considering design axial stress $=1+\mathrm{M}_{0} / \mathrm{M}_{\mathrm{d}}=<2\left(\mathrm{~N}_{\mathrm{d}}{ }^{\prime}=>0\right)$ or $1+2 \mathrm{M}_{0} / \mathrm{M}_{\mathrm{d}}=>0\left(\mathrm{~N}_{\mathrm{d}}{ }^{\prime}<0\right), \mathrm{b}_{\mathrm{w}}$ : width of section, d: effective depth, $p_{c}=A_{s} /\left(b_{w} d\right), A_{s}$ : sectional area of tensile reinforcements, $M_{d}$ : design moment, $\mathrm{M}_{0}$ : decompression moment, $\mathrm{N}_{\mathrm{d}}$ : design axial force, and $\gamma_{\mathrm{b}}$ : member safety factor.

The value of $\mathrm{V}_{\mathrm{s}}(\mathrm{N})$ : shear strength held by transverse bars is estimated by Eq.(2) in case that transverse reinforcements are arranged rectangular to the column axis.

$$
V_{s}=A_{w} \cdot f_{w y d} / s_{s} \cdot z / \gamma_{b}
$$

where, $A_{w}$ : sectional area of transverse reinforcements in the length of " $s_{s}$ ", $f_{w y d}$ : yield strength of transverse reinforcement, $\mathrm{s}_{\mathrm{s}}$ : spacing of transverse reinforcement, $\mathrm{z}=\mathrm{d} / 1.15$, $\mathrm{d}$ : effective depth, and $\gamma_{\mathrm{b}}$ : member safety factor.

\section{Evaluation of ductility}

Ductility ratio of retrofitted columns by the reinforced concrete jacket method is estimated by Eqns.(3) and (4).

$$
\begin{aligned}
& \mu_{\mathrm{d}}=\left(\mu_{0} \cdot \delta_{\mathrm{y} 0}+\delta_{\mathrm{u} 1}\right) /\left(\delta_{\mathrm{y} 0}+\delta_{\mathrm{y} 1}\right) \\
& \mu_{0}=-1.6+5.6 V_{\mathrm{yd}} \mathrm{a} / \mathrm{M}_{\mathrm{ud}}+\left(11.4 \mathrm{p}_{\mathrm{s}}-1.4\right) \mathrm{p}_{\mathrm{s}}
\end{aligned}
$$

where, $\mu_{\mathrm{d}}$ : design ductility ratio of retrofitted column, $\delta_{\mathrm{y} 0}$ : deformation at which the reinforcements that have the largest effective depth reach yielding, $\delta_{\mathrm{y} 1}$ : rotational displacement by pull-out of axial reinforcements from the footing at yielding, $\delta_{\mathrm{u} 1}$ : rotational displacement by pull-out of axial reinforcements from the footing at the ultimate state, $V_{y d}$ : shear capacity estimated by Eqns.(1) and (2), a: spear span, $\mathbf{M}_{\mathrm{ud}}$ : flexural capacity, $\mathrm{p}_{\mathrm{s}}$ : transverse reinforcements ratio.

\section{Steel jacket method}

\section{Outline of steel jacket method}


Use of steel jacket method has been common for these types of seismic retrofitting because this method is advantageous in terms of cost and execution workability. Fig.3 shows the outline of the steel jacket method. In this method, two U-shaped steels are set by a crane (Photo 3), and joined by field welding or mechanical joints. And, retrofitting works are completed by mortar casting between retrofitting steels and column surfaces. Fig.4 shows mechanical joints developed by the authors for this retrofitting method. These mechanical joints eliminate the need for melting works on site, thereby improving executability.
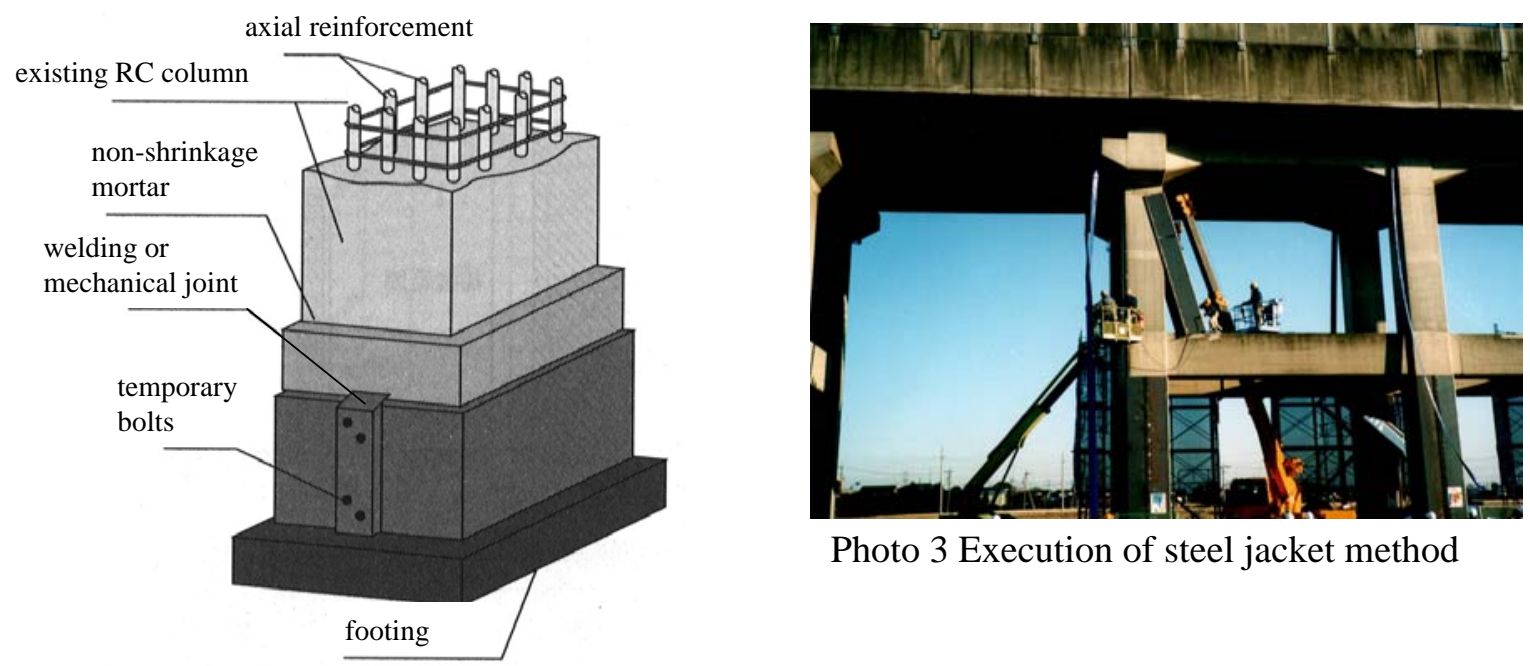

Photo 3 Execution of steel jacket method

Fig.3 Outline of steel jacket method

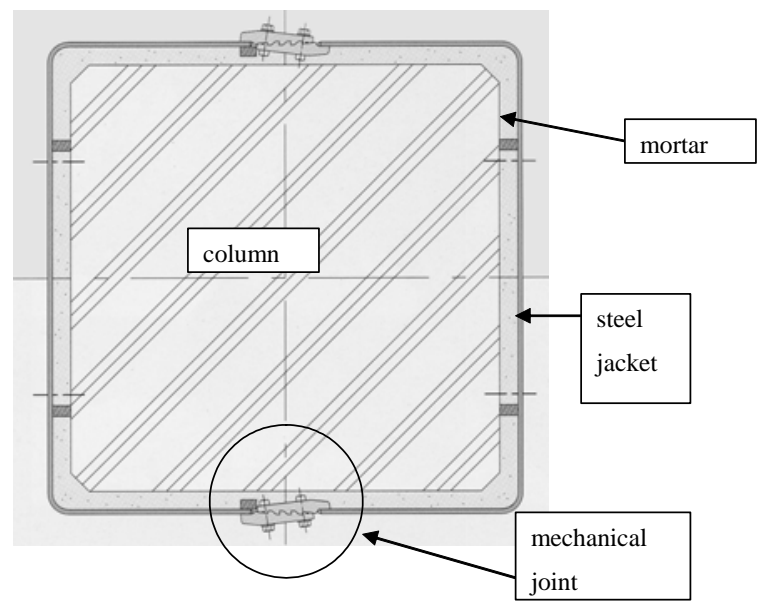

Fig.4 Mechanical joint of steel jacket method

\section{Evaluation of flexural and shear capacity}

In general, retrofitting steel plates are not anchored at a footing. Therefore, flexural capacity is estimated without retrofitting steel plates. The shear capacity $\mathrm{V}_{\mathrm{yd}}$ is assumed as the sum of $\mathrm{V}_{\mathrm{c}}$ : shear strength held by concrete, $\mathrm{V}_{\mathrm{s}}$ : shear strength held by transverse reinforcements and $\mathrm{V}_{\mathrm{r}}$ : shear strength held by retrofitting steel plates. The value of $\mathrm{V}_{\mathrm{r}}(\mathrm{N})$ is estimated by the Eq.(5).

$$
V_{r}=2 t h \cdot f_{\text {rvyd }} / \gamma_{b}
$$

where, $f_{\text {rvyd }}$ : design shear yield strength of retrofitting steel plates $=f_{r y d} / 3^{1 / 2}, f_{\text {ryd }}$ : design tensile yield strength of retrofitting steel plates, h: sectional height of retrofitted column, t: thickness of steel plate, 
and $\gamma_{\mathrm{b}}$ : member safety factor.

\section{Evaluation of ductility}

Ductility ratio of retrofitted columns by the steel jacket method is estimated by Eq.(6).

$$
\begin{aligned}
\mu_{\mathrm{rd}}= & \left(3.1 \mathrm{~V}_{\mathrm{r}} \cdot \mathrm{a} / \mathrm{M}_{\mathrm{ryd}}+5.9\right)(-42.6 \mathrm{t} / \mathrm{h}+1.2)(-0.052 \mathrm{~b} / \mathrm{h}+1.1) \\
& \text { with } 0.002=<\mathrm{t} / \mathrm{h}<=0.014,1.0=<\mathrm{b} / \mathrm{h}<=4.0,2,5=<\mathrm{a} / \mathrm{d}<=4.0
\end{aligned}
$$

where, $\mu_{\mathrm{rd}}$ : design ductility ratio retrofitted by the steel jacket method, $\mathrm{V}_{\mathrm{r}}$ : shear strength held by retrofitting steel plates by Eq.(5), a: shear span, $\mathrm{M}_{\mathrm{ryd}}$ : flexural yield capacity, t: thickness of steel plates, h: sectional height of retrofitted column, and b: sectional width of retrofitted column.

\section{Carbon fiber sheet jacket method}

\section{Outline of carbon fiber sheet jacket method}

The carbon fiber sheet jacket method is scarcely used for railway structures because an execution cost of this method is much higher than that of the steel jacket method. However, this method is adopted where large construction machinery like a crane can not be used. This situation is almost the same to the aramid fiber sheet jacket method mentioned next.

\section{Evaluation of flexural and shear capacity}

Flexural capacity is estimated by the same way in case of the steel jacket method. The shear capacity $\mathrm{V}_{\mathrm{yd}}$ is assumed as the sum of $\mathrm{V}_{\mathrm{c}}$ : shear strength held by concrete, $\mathrm{V}_{\mathrm{s}}$ : shear strength held by transverse reinforcements and $\mathrm{V}_{\mathrm{CFd}}$ : shear strength held by retrofitting carbon fiber sheets. The value of $\mathrm{V}_{\mathrm{CFd}}(\mathrm{N})$ is estimated by the Eq.(7) in case that carbon sheets are arranged rectangular to the column axis.

$$
\mathrm{V}_{\mathrm{CFd}}=\mathrm{K} \cdot \mathrm{A}_{\mathrm{CF}} \cdot \mathrm{f}_{\mathrm{CFud}} / \mathrm{S}_{\mathrm{CF}} \cdot \mathrm{z} / \gamma_{\mathrm{b}}
$$

where, $A_{C F}$ : sectional area of carbon fiber sheets per unit width with $0.002=>p_{C F w}=>0.00035$, $\mathrm{P}_{\mathrm{CFw}}=\mathrm{A}_{\mathrm{CF}} /\left(\mathrm{b} \mathrm{S}_{\mathrm{CF}}\right)$, b: sectional width, $\mathrm{K}$ : correction factor of carbon fiber sheet (=0.8), $\mathrm{S}_{\mathrm{CF}}$ : unit width of carbon fiber sheet, $\gamma_{\mathrm{b}}$ : member safety factor.

\section{Evaluation of ductility}

Ductility ratio retrofitted columns by the carbon fiber sheet method is estimated by Eq.(8).

$$
\mu_{\mathrm{CFd}}=2.8+1.15\left(\mathrm{~V}_{\mathrm{CFd}} \mathrm{a} / \mathrm{M}_{\mathrm{CFud}}\right)=<10.0
$$

where, $\mu_{\mathrm{CFd}}$ : design ductility ratio retrofitted by the carbon fiber sheet jacket method, $\mathrm{V}_{\mathrm{CFd}}$ : shear strength held by carbon fiber sheets by Eq.(7), $\mathrm{M}_{\mathrm{CFud}}$ : flexural capacity.

\section{Aramid fiber sheet jacket method}

\section{Evaluation of flexural and shear capacity}

Flexural capacity is estimated by the same way in case of the steel jacket method. The shear capacity $\mathrm{V}_{\mathrm{yd}}$ is assumed as the sum of $\mathrm{V}_{\mathrm{c}}$ : shear strength held by concrete, $\mathrm{V}_{\mathrm{s}}$ : shear strength held by transverse reinforcements and $\mathrm{V}_{\mathrm{AFd}}$ : shear strength held by retrofitting aramid fiber sheets. The value of $\mathrm{V}_{\mathrm{AFd}}(\mathrm{N})$ is estimated by the Eq.(9).

$$
\mathrm{V}_{\mathrm{AFd}}=\mathrm{K} \cdot \mathrm{A}_{\mathrm{AF}} \cdot \mathrm{f}_{\mathrm{AFud}} / \mathrm{S}_{\mathrm{AF}} \cdot \mathrm{z} / \gamma_{\mathrm{b}}
$$

where, $\mathrm{A}_{\mathrm{AF}}$ : sectional area of aramid fiber sheets per unit width, $\mathrm{K}$ : correction factor of aramid fiber sheet $(=0.4), S_{A F}$ : unit width of aramid fiber sheet, $\gamma_{\mathrm{b}}$ : member safety factor. 


\section{Evaluation of ductility}

Ductility ratio retrofitted columns by the aramid fiber sheet method is estimated by Eq.(10).

$$
\mu_{\mathrm{AFd}}=2.2+3.2\left(\mathrm{~V}_{\mathrm{AFd}} \mathrm{a} / \mathrm{M}_{\mathrm{AFud}}\right)=<10.0
$$

where, $\mu_{\mathrm{AFd}}$ : design ductility ratio retrofitted by the aramid fiber sheet jacket method, $\mathrm{V}_{\mathrm{AFd}}$ : shear strength held by aramid fiber sheet by Eq.(9), $\mathrm{M}_{\mathrm{AFud}}$ : flexural capacity.

\section{RB method}

\section{Outline of the RB method}

Fig.5 shows the outline of the RB method. In this method, external lateral reinforcements are arranged around a RC column and anchored at the four corners with L-shaped steels. This method can be executed purely by hand and is easily applied to existing RC columns in confined spaces. Fig.6 shows the execution flow. Photo 4 shows an example of completion of retrofitting works.
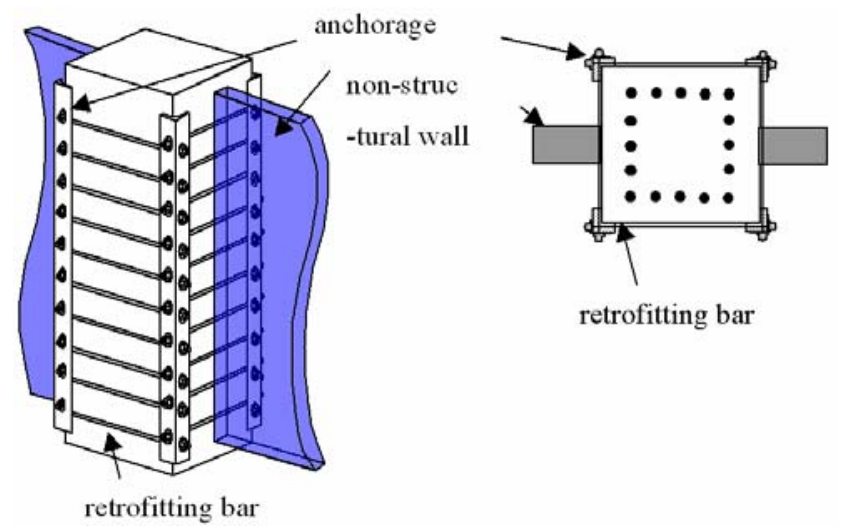

Fig.5 Outline of RB method

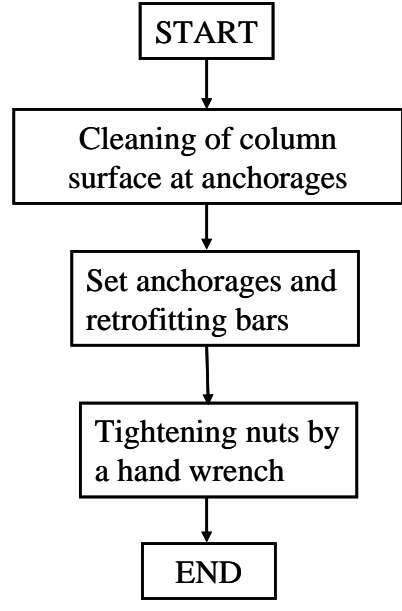

Fig.6 Execution flow of RB method

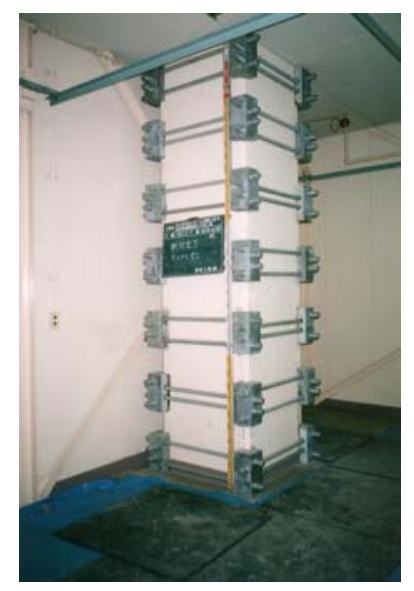

Photo 4 RB method completed

\section{Evaluation of flexural and shear capacity}

Flexural capacity is estimated by the same way in case of the steel jacket method. The shear capacity $\mathrm{V}_{\mathrm{yd}}$ is assumed as the sum of $\mathrm{V}_{\mathrm{c}}$ : shear strength held by concrete, $\mathrm{V}_{\mathrm{s}}$ : shear strength held by transverse 
reinforcements arranged in the existing section, and $\mathrm{V}_{\mathrm{RB}}$ : shear strength held by external retrofitting bars. $\mathrm{V}_{\mathrm{RB}}$ is also estimated by Eq.(2) by a truss analogy.

\section{Evaluation of ductility}

In this method, ductility ratio becomes higher than 10 if the following inequality is satisfied in the top and bottom regions of the column with length of 2D (D: height of column section).

$$
\gamma_{\mathrm{i}} \cdot \mathrm{V}_{\mathrm{yd}} / \mathrm{V}_{\mathrm{mu}}>1.5
$$

where, $\gamma_{\mathrm{i}}$ : structural safety factor, $\mathrm{V}_{\mathrm{yd}}$ : shear capacity of retrofitted column by the RB method, $\mathrm{V}_{\mathrm{mu}}=\mathrm{M}_{\mathrm{ud}} / \mathrm{a}, \mathrm{M}_{\mathrm{ud}}$ : flexural capacity, a: shear span.

This design method can be applied to RC columns and piers on condition that compressive stress caused by permanent loads is smaller than $3 \mathrm{~N} / \mathrm{mm}^{2}$.

\section{Single-face method}

\section{Outline of the single-face method}

Fig.7 shows the schematic drawing of the single-face method. This method uses a steel plate and reinforcing bars and allows execution of retrofitting work from only one face of the RC column section. There are many cases such as Photo 5 in which one face of the RC column is exposed where spaces under superstructures are used for stores and offices. In such cases, seismic retrofitting works can be carried out easily by the single-face method. Fig. 8 is the execution flow and Photo 6 is an example of completion of retrofitting works.

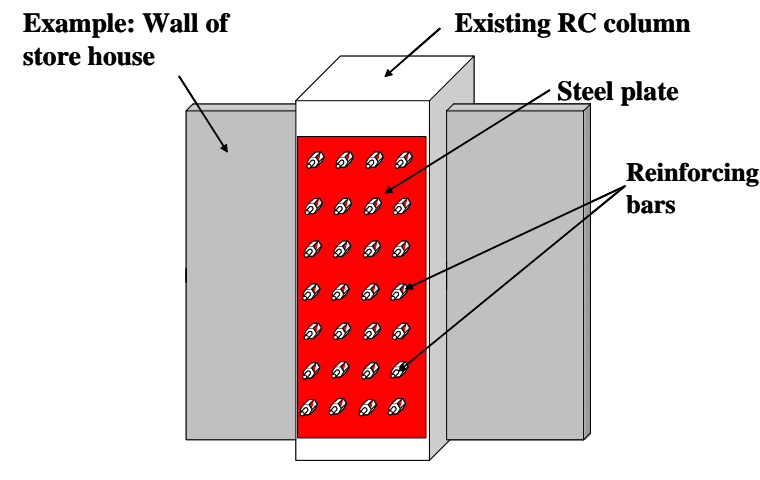

Fig.7 Outline of single-face method

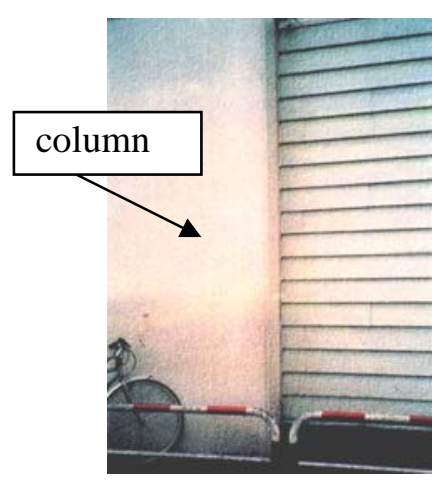

Photo 5 Example of column where spaces under structures are used

\section{Evaluation of flexural and shear capacity}

Flexural capacity is estimated by the same way in case of the steel jacket method. In the design of retrofitting bars, the shear capacity $\mathrm{V}_{\mathrm{yd}}$ is assumed as the sum of $\mathrm{V}_{\mathrm{c}}$ : shear strength held by concrete, $\mathrm{V}_{\mathrm{s}}$ : shear strength held by transverse reinforcements arranged in the existing section, and $\mathrm{V}_{\mathrm{OB}}$ : shear strength held by retrofitting bars. $\mathrm{V}_{\mathrm{OB}}$ is also estimated by a truss analogy. In the design of the retrofitting plate, the shear capacity $V_{y d}$ is assumed as the sum of $V_{c}$ : shear strength held by concrete, $\mathrm{V}_{\mathrm{s}}$ : shear strength held by transverse reinforcements arranged in the existing section, and $\mathrm{V}_{\mathrm{OP}}$ : shear strength held by the retrofitting plate. $\mathrm{V}_{\mathrm{OP}}(\mathrm{N})$ is estimated by Eq.(12).

$$
\mathrm{V}_{\mathrm{OP}}=\mathrm{f}(\mathrm{s}) \cdot \mathrm{V}_{\mathrm{sy}}
$$

where, $\quad \mathrm{V}_{\mathrm{sy}}=\mathrm{f}_{\mathrm{vy}} \mathrm{t}_{\mathrm{w}} \mathrm{z}_{\mathrm{w}} / \gamma_{\mathrm{b}}, \quad \mathrm{f}(\mathrm{s})=2.7+0.16 \mathrm{k}-0.68(\mathrm{a} / \mathrm{d}) \quad$ with $\quad 0.6=<\mathrm{f}(\mathrm{s})<=2.5, \quad 1.0=<\mathrm{a} / \mathrm{d}<=3.5, \quad$ and $2.0=<\mathrm{k}=<7.0, \mathrm{f}_{\mathrm{vy}}=\mathrm{f}_{\mathrm{syk}} / 3^{1 / 2} / \gamma_{\mathrm{s}}, \mathrm{t}_{\mathrm{w}}$ : thickness of retrofitting plate, $\mathrm{z}_{\mathrm{w}}$ : width of retrofitting plate, $\gamma_{\mathrm{b}}$ : 

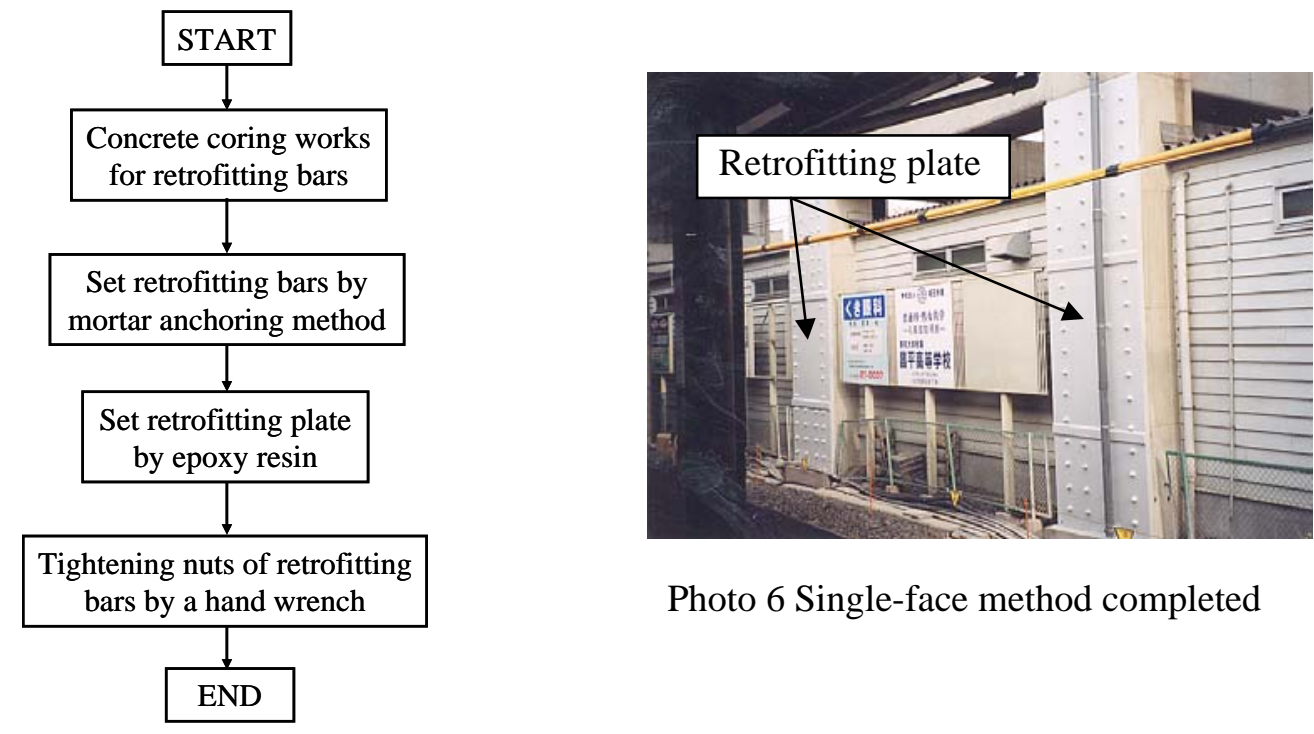

Photo 6 Single-face method completed

Fig.8 Execution flow of single-face metnod

member safety factor, $k$ : modifier considering plate thickness $=t_{w} \cdot z_{w} /\left(b_{w} \cdot d\right), b_{w}$ : width of section, $d$ : effective depth, a: shear span, and $\gamma_{s}$ : material safety factor.

\section{Evaluation of ductility}

Ductility ratio becomes higher than 10 if the following inequalities are satisfied in the top and bottom regions of the column with length of 2D (D: height of column section). Ineq.(13) is applied in the design of retrofitting bars and Ineq.(14) in the design of the retrofitting plate.

$$
\begin{aligned}
& \gamma_{\mathrm{i}} \cdot \mathrm{V}_{\text {yd }} / \mathrm{V}_{\text {mu }}>2.0 \\
& \gamma_{\mathrm{i}} \cdot \mathrm{V}_{\text {yd }} / \mathrm{V}_{\text {mu }}>1.4
\end{aligned}
$$

where, $\gamma_{\mathrm{i}}$ : structural safety factor, $\mathrm{V}_{\mathrm{yd}}$ : shear capacity of retrofitted column, $\mathrm{V}_{\mathrm{mu}}=\mathrm{M}_{\mathrm{ud}} / \mathrm{a}, \mathrm{M}_{\mathrm{ud}}$ : flexural capacity, a: shear span.

Then, the applied condition is the same to the RB method.

\section{CONCLUSIONS}

This paper reports on a general seismic retrofitting design flow of existing RC columns and piers of railway structures and representative seismic retrofitting methods in East Japan Railway Company.

Since 1995, seismic retrofitting works of railway structures have been carried out vigorously. However, these works are not completed. Therefore, developments of new methods which are more advantageous than existing seismic retrofitting methods mentioned in this paper are strongly required.

\section{REFERENCES}

Railway Technical Research Institute, Design standard for railway structures (Concrete structures), 1992.10

Railway Technical Research Institute, Design standard for railway structures (Seismic design), 
1999.10

Railway Technical Research Institute, Guidelines for seismic retrofit design and work of the existing railway concrete viaducts piers -Retrofitting with steel jacket method, 1999.7

Railway Technical Research Institute, Guidelines for seismic retrofit design and work of the existing railway concrete viaducts piers - Retrofitting with carbon fiber sheet jacket method, 1996.7

Railway Technical Research Institute, Guidelines for seismic retrofit design and work of the existing railway concrete viaducts piers -Retrofitting with aramid fiber sheet jacket method, 1996.11

Tsuyoshi T., Ishibashi T., Kobayashi M. and Tatsuki S., "An experimental study on seismic retrofitting methods for existing reinforced concrete columns with external lateral reinforcements anchored at four corners of columns", Proceedings of JSCE, No.662/V-49, 205-216, 2000.11

Kobayashi K. and Ishibashi T., "An experimental study on effect of seismic retrofitting of existing reinforced concrete columns by reinforcing bars set from one face", Proceedings of JSCE, No.683/V-52, 91-102, 2001.8

Kobayashi K. and Ishibashi T., "An experimental study on effect of seismic retrofitting of existing reinforced columns by steel plate put on one face”, Proceeding of JSCE, No.683/V-52, 75-89, 2001.8

(Submitted: March 31, 2004)

(Accepted: June18, 2004)

Copyright JAEE 